\title{
REVIEW
}

\section{The potential of unmanned aerial systems for sea turtle research and conservation: a review and future directions}

\author{
ALan F. Rees ${ }^{1, *}$, Larisa Avens ${ }^{2}$, Katia Ballorain ${ }^{3,4}$, Elizabeth Bevan ${ }^{5}$, \\ Annette C. Broderick ${ }^{1}$, Raymond R. Carthy ${ }^{6}$, Marjolijn J. A. Christianen ${ }^{\text {7,8 }}$, \\ Gwénaël Duclos ${ }^{9}$, Michael R. Heithaus ${ }^{10}$, David W. Johnston ${ }^{11}$, Jeffrey C. Mangel ${ }^{1,12}$, \\ Frank Paladino ${ }^{13}$, Kellie Pendoley ${ }^{14}$, Richard D. Reina ${ }^{15}$, Nathan J. Robinson ${ }^{16}$, \\ Robert Ryan $^{17}$, Seth T. Sykora-Bodie ${ }^{11}$, Dominic Tilley ${ }^{1}$, Miguel R. Varela ${ }^{1}$, \\ Elizabeth R. Whitman ${ }^{10}$, Paul A. Whittock ${ }^{14}$, Thane Wibbels ${ }^{5}$, Brendan J. Godley ${ }^{1}$ \\ ${ }^{1}$ Marine Turtle Research Group, Centre for Ecology and Conservation, College of Life and Environmental Sciences, \\ University of Exeter, Penryn Campus, Cornwall TR10 9FE, UK \\ Addresses for other authors are given in Supplement 1 at www.int-res.com/articles/suppl/n035p081_supp/
}

\begin{abstract}
The use of satellite systems and manned aircraft surveys for remote data collection has been shown to be transformative for sea turtle conservation and research by enabling the collection of data on turtles and their habitats over larger areas than can be achieved by surveys on foot or by boat. Unmanned aerial vehicles (UAVs) or drones are increasingly being adopted to gather data, at previously unprecedented spatial and temporal resolutions in diverse geographic locations. This easily accessible, low-cost tool is improving existing research methods and enabling novel approaches in marine turtle ecology and conservation. Here we review the diverse ways in which incorporating inexpensive UAVs may reduce costs and field time while improving safety and data quality and quantity over existing methods for studies on turtle nesting, at-sea distribution and behaviour surveys, as well as expanding into new avenues such as surveillance against illegal take. Furthermore, we highlight the impact that high-quality aerial imagery captured by UAVs can have for public outreach and engagement. This technology does not come without challenges. We discuss the potential constraints of these systems within the ethical and legal frameworks which researchers must operate and the difficulties that can result with regard to storage and analysis of large amounts of imagery. We then suggest areas where technological development could further expand the utility of UAVs as data-gathering tools; for example, functioning as downloading nodes for data collected by sensors placed on turtles. Development of methods for the use of UAVs in sea turtle research will serve as case studies for use with other marine and terrestrial taxa.
\end{abstract}

KEY WORDS: Drone $\cdot$ UAV · Aerial survey $\cdot$ Sea turtle $\cdot$ Ecology $\cdot$ Behaviour $\cdot$ Conservation · Population biology 


\section{INTRODUCTION}

Remote sensing data are becoming increasingly important for understanding the spatial ecology of marine systems and, when used in tandem with tracking data, can provide important insights into the specific environmental niches and spatial distribution of target species (fish: Druon et al. 2016; sea turtles: Thums et al. 2017; sea birds: Afán et al. 2014; seals: Nachtsheim et al. 2017; cetaceans: do Amaral et al. 2015). These data have traditionally been obtained from Earth observation satellites that report data on global scales but at coarse resolutions (Kuenzer et al. 2014) and are subject to atmospheric interference from clouds and humidity. For over a decade, unmanned aerial vehicles (UAVs, also known as drones) have been identified as tools for wildlife research (Jones et al. 2006). Furthermore, with the continued improvement of flight and control technologies as well as sensor capabilities, their use is becoming increasingly common for ecological studies. UAVs are helping revolutionise the field of spatial ecology (Anderson \& Gaston 2013), and are proving particularly useful for studying biodiversity and habitats that are difficult or dangerous to access from the ground (Chabot \& Bird 2015).

UAV use for wildlife monitoring has been adopted for a variety of taxa and to answer a range of ecological questions. Wildlife surveying has included size and abundance estimates of nesting bird colonies and seal haul-outs (Goebel et al. 2015), dugong counts (Hodgson et al. 2013), orangutan nest identification (Koh \& Wich 2012), nesting behaviour of crocodiles (Evans et al. 2015) and assessing spatial variation in abundance of reef sharks (Kiszka et al. 2016). Furthermore, UAV data have been used to assess the effects that wildlife may have on their surroundings, such as changes to local landscapes post-beaver introduction (Puttock et al. 2015) and crop damage by wild boar (Michez et al. 2016).

The design of UAVs falls into 2 main categories, fixed-wing and multi-rotor aircraft, both having advantages and limitations. Flight characteristics of fixed-wing UAVs are more complex than those of multi-rotor UAVs, requiring constant forward motion to remain airborne and a larger area for take-off and landing. Fixed-wings have longer flight times ( $\geq 45 \mathrm{~min}$ ) and have less dramatic landings following power failure compared to multi-rotor types that may remain stationary in the air, have shorter flight times ( 20 min) but crash vertically upon power failure. Multi-rotor UAVs with 6 or more rotors can sometimes withstand failure of one of the motors, but the more common 4-rotor 'quad copters' do not have this capability. However, battery failure is more common than motor failure and fixed-wing UAVs have better crash characteristics in these circumstances. For reviews of typical, readily available UAV systems see Anderson \& Gaston (2013), Linchant et al. (2015) and DeBell et al. (2016). It should be noted that there is growing investment in developing aircraft that blur the lines between multi-rotor and fixed-wing UAVs. These aircraft, often referred to as transitional vertical take-off and landing (transitional VTOL) platforms, combine the flexibility of multi-rotors with the endurance of fixed-wings. These platforms may be especially attractive to marine turtle researchers because they can be launched and recovered from a small boat, yet sample large areas efficiently. Kites (Bryson et al. 2013, Duffy \& Anderson 2016) and balloons (Miyamoto et al. 2004) are other simple and inexpensive modes of obtaining aerial data but are more limited than remotely controlled UAVs (e.g. short range and only capable of flying in limited weather conditions) and will not be covered further here.

UAVs consist of airframes with sensors for data collection appropriate to the mission objectives. For example, standard RGB (red, green, blue) images and video are used in behavioural sampling and habitat assessments (Puttock et al. 2015) including 3-dimensional (3D) topographical reconstruction through the structure from motion (SfM) approach (Mancini et al. 2013); multispectral images (near-infrared and RGB) are used in vegetation assessments (Strecha et al. 2012, Knoth et al. 2013); and thermal images can be used for animal enumeration (Seymour et al. 2017) and aquatic environment assessments (Jensen et al. 2012). Light detection and ranging (LiDAR) sensors are also used to generate 3D models that can define topography and contribute towards determining vegetation structure (Dandois \& Ellis 2010).

Control of UAVs is achieved through 2 main mechanisms, often employed in tandem: (1) remote control by a ground-based pilot and (2) autonomous flight of predetermined routes generated in ground control (GC) software from a personal computer or tablet device, in total known as an unmanned aerial system (UAS). Many UAVs are capable of relaying live video feeds from the UAV's camera back to the pilot's controller, creating a first-person view (FPV) of the flight. This functionality depends on the specifications of the telemetry system incorporated on the UAV, and FPV range may vary from $<1$ to $10 \mathrm{~s}$ of $\mathrm{km}$ (see https://youtu.be/aqMm_gzuRYI for an example of $100 \mathrm{~km}$ range FPV, but note that such a long-range flight would be illegal in many jurisdictions, and the 
authors do not condone flights breaking applicable local/national legislation). Sea turtles often reside in remote marine habitats (Bolten 2003) and nest over large areas (Miller 1997), making thorough surveying for turtle presence using traditional methods time consuming (ground-based nesting beach studies), costly (aerial surveys employing piloted aircraft) and potentially dangerous (e.g. crocodiles or illicit turtle hunters on beaches). Hence, there are clear benefits in terms of time, effort, cost and risk, for using UAVs as data collection platforms across a range of sea turtle habitats. Furthermore, traditional aerial surveys present challenges in terms of logistics and incur significant risks to researchers (Sasse 2003), especially in situations where flights are conducted over water. Surveys conducted via UAVs can reduce these risks. They allow researchers to avoid the logistical problems associated with data acquisition from occupied aircraft or satellites and result in 'on-demand' remote sensing for marine turtle research.

These new methods and opportunities for research mean that vast, novel datasets are generated and require analysis. Still images and high-resolution video from a single flight may generate files totalling several gigabytes; thus, high-powered, well-resourced IT infrastructure and software are required to store and process UAS data. Additionally, manual recording observations from captured data is laborious, time-consuming work that contributes to the overall complexity of exploiting these novel data sets.

Despite the great potential for UAVs to benefit sea turtle research, only 6 articles featuring their use have been published in the scientific literature (Bevan et al. 2015, 2016, Brooke et al. 2015, Schofield et al. 2017a,b, Sykora-Bodie et al. 2017). Furthermore, these articles only cover identification and monitoring of sea turtles in nearshore habitats, and represent a limited range of the potential scope of UAVs as ecological tools.

We expect that the incorporation of UASs into the sea turtle researcher's toolbox will revolutionise traditional data collection methods and facilitate acquisition of a suite of previously unobtainable data sets to be used for monitoring and conservation that will help advance priority sea turtle conservation fields (Rees et al. 2016). Here, we review the potential advances that the use of small, low-cost UAVs may provide over existing sea turtle research methods (see the video in Supplement 2 at www.int-res.com/ articles/suppl/n035p081_supp/). We also note the use of UAVs for raising awareness and highlighting future directions for methodological and technological advances to improve data collection for both sea turtle and multi-taxon studies.

\section{REVIEW OF CURRENT POTENTIAL}

\section{Suitable UAV configurations for conducting surveys at various geographic ranges}

The functionality and logistics of basic surveying methods using UAVs can be categorised, somewhat arbitrarily, by survey distance. The resulting UAV configurations, for short-, mid- and long-range surveys, listed below, should be accepted as guidelines that are likely to change as UAV endurance and capabilities improve.

For each of the distance categories below, it is important that videos or images are recorded throughout the flight so that the data gathered can be reviewed by more than one researcher to obtain consensus of observed findings, and can be archived for future reanalysis and possible repurposing. Detail recorded by the UAV is constrained by image resolution. Images of 8.3 megapixels can be extracted from ' $4 \mathrm{~K}$ ' resolution video footage, whereas most sensors are capable of capturing at least 12 megapixel still images. The usefulness of UAV-acquired data depends on the subject being visible. Therefore, areas where turtle nesting occurs within vegetation or where turtles are camouflaged over large seagrass beds (or other dark substrate), or masked in deep or very turbid waters are less suited for this type of work.

'Short range' surveys $(<1.5 \mathrm{~km})$. Multi-rotor UAVs. These may be flown remotely or autonomously. An FPV-enabled system can provide the ground patrol team with a live stream from the UAV's camera. Shorter surveys within this range may keep the UAV in line-of-sight, which simplifies remote flight options.

'Mid-range' surveys (between 1.5 and $10 \mathrm{~km}$ ). Multi-rotor or fixed-wing UAVs. Under certain conditions, FPV remote piloting of the UAV may be feasible, but most survey missions likely require autonomous flights to cover more logistically difficult to access, and/or dangerous areas.

'Long range' surveys $(>\mathbf{1 0} \mathbf{~ k m})$. Fixed wing. Very unlikely to require FPV capabilities, therefore autonomous pre-planned flights are the norm. These surveys would be applicable for data gathering and archiving from large stretches of inaccessible coastline, offshore islands and open sea.

\section{Beach and coastline surveys}

Surveying sea turtle nesting activity at index sites or over more extensive coastlines is the most common 
method of monitoring population status and trends. Beaches are typically traversed at predefined intervals and evidence of sea turtle nesting is recorded (Schroeder \& Murphy 1999). The amount of detail recorded depends on the frequency and purpose of the survey, but at minimum consists of species identification and track and nest counts (Lauret-Stepler et al. 2007, Witherington et al. 2009, Bourjea et al. 2015, Metcalfe et al. 2015). These surveys are sensitive to the completeness of beach coverage (Reina et al. 2002) and are most commonly performed on foot or by vehicle or, due to expense and logistical complications, less commonly undertaken using manned aircraft (e.g. Witt et al. 2009); see Schroeder \& Murphy (1999) for an overview of methods.

Incorporating UASs into coastal surveying for sea turtle nesting activity (Fig. 1) or other occurrences such as turtle strandings can reduce costs, simplify methods, enhance data acquisition and create a permanent visual archive of actual and potential nesting habitats. The ability to characterise stranding trends is important for early identification of potential sources of mortality. Many turtles strand alive, e.g. from cold stunning (Milton \& Lutz 2003), and UASs could be instrumental in rapid identification of stranding hotspots and recovery of these turtles for rehabilitation, through scoping surveys flown over potential stranding locations.

Benefits of UAV use for monitoring sea turtle nesting activity in combination with or replacing established methods include:

For short range surveys. Live view or rapid post-survey review of visual data would permit more efficient ground patrol activities, thus enhancing such tasks as transporting nest protection equipment and saving staff time by not patrolling areas without nesting activity. Surveying beaches intersected by tidal rivers and estuaries is also simplified. The data could also contribute to an archive of contemporary environmental conditions such as sea state and prevalence of marine litter (Jang et al. 2015), or stranded Sargassum floats that can also lead to entrapment of turtle hatchlings.

Medium and long range surveys. These surveys would target more logistically difficult to access, even dangerous, areas to record data that would otherwise remain elusive.

Nocturnal surveys. Nesting turtles can be identified on the beach at night using a UAV equipped with a low-light optical or thermal camera (Fig. 2). This method could be used to generate nesting turtle counts on established nesting beaches where access to the beach is logistically demanding or dangerous, or where high nesting densities make ground surveys difficult. Turtles identified by their heat signatures are tallied manually by one or more researchers, either during the UAV flight in near real-time, from video replay at a later date, or through machine learning techniques, such as image and pattern recognition.

\section{In-water surveys}

Sea turtles generally spend the vast majority of their lives in the marine realm, except for a short period as hatchlings crawling from the nest to the surf, and for adult females when they return to the beach to deposit clutches of eggs. In-water sea turtle surveys are therefore undertaken to gather data on turtle behaviour, density and distribution in cryptic and otherwise inaccessible habitats. Generally, when turtle capture is a key part of research such as for capture-mark-recapture studies (e.g. Rees et al. 2013) or relatively small areas are to be surveyed (Bresette et al. 2010), these are carried out via boatbased surveys. In other cases, turtle distribution assessments are undertaken in manned aircraft (e.g. Jean et al. 2010, Seminoff et al. 2014), but exceptions using boats exist (see Eguchi et al. 2007). In-water data collection is also less commonly accomplished using SCUBA diving or snorkelling (Schofield et al. 2006, Bell et al. 2008, Ballorain et al. 2013, Chassagneux et al. 2013, Williams et al. 2015, Strindberg et al. 2016, Weber et al. 2017).

Given suitable conditions of good water clarity, low wind and minimal sun glint, UASs can help transform in-water turtle studies with hitherto unobtainable data resolution and viewpoints at costs that undercut alternative methods.

Turtle densities and distribution in foraging areas. Like established boat and aerial surveys, UAVs can fly predefined transects, recording high-definition video or taking images at regular intervals over marine habitats (Ballorain et al. 2016). Moreover, some UAVs can be launched from boats to combine the advantages of both methods. A transect's visual strip width will depend on the field-of-view and angle of the UAV sensor and altitude during flight and would need to be confirmed for each surveying regime (Fig. 3). The visual data are reviewed post-flight by one or more individuals, and turtle observations can be georeferenced from the video and time-synced GPS survey records from the UAV or from geotagged still images (Sykora-Bodie et al. 2017). Abundance estimations can then be carried out as per standard aerial survey methods (Fuentes et al. 2015), ensuring that the effect of dive behaviour on the visibility of turtles is properly 


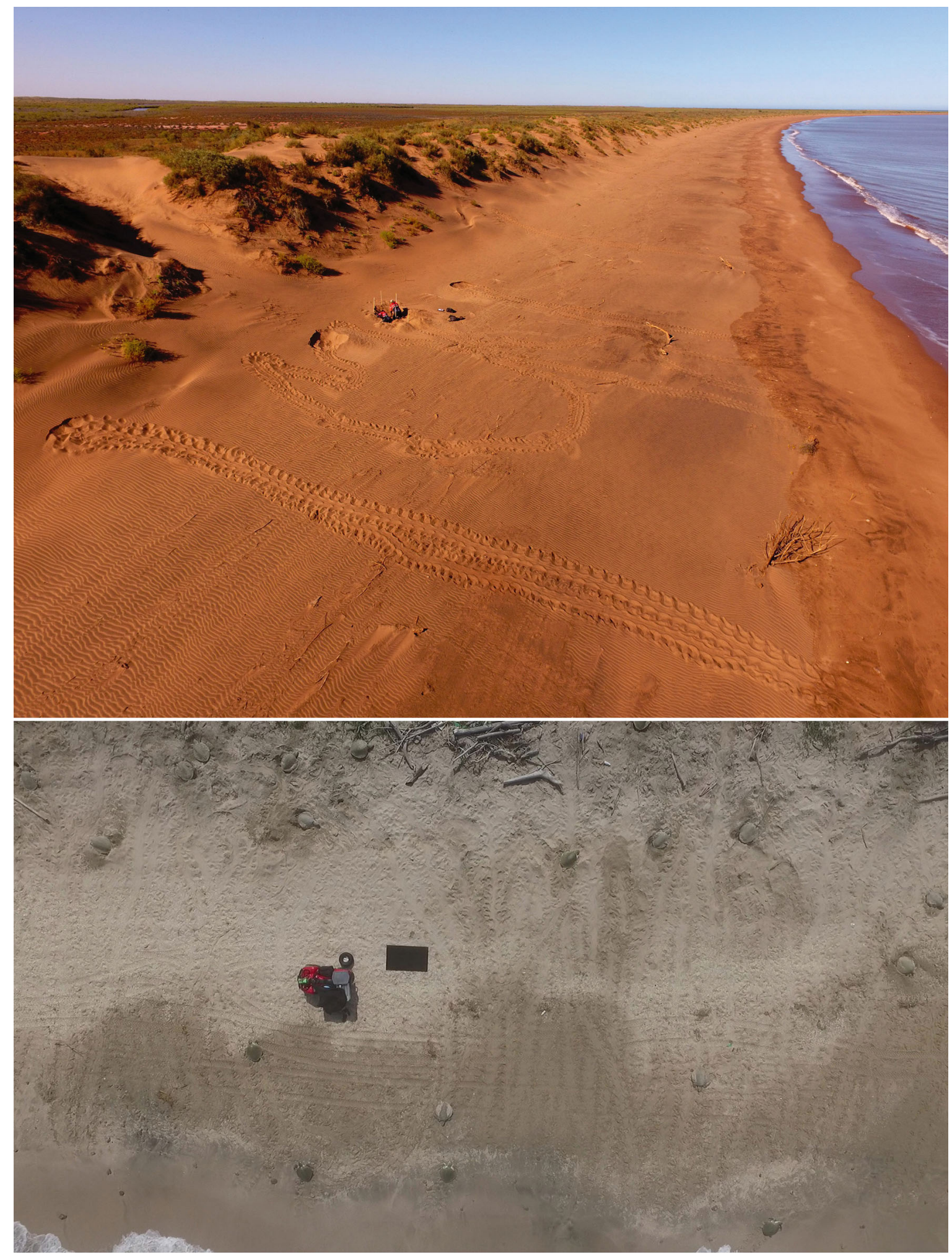

Fig. 1. Sea turtle nesting activity recorded from an unmanned aerial vehicle (UAV). Upper image: Flatback turtle Natator depressus tracks and research team on the Pilbara coast, Australia (Photo: R. Ryan, using a DJI Phantom 4 with an on-board 12.4 MP fixed-focus camera at $30 \mathrm{~m}$ ). Lower image: Kemp's ridley arribada occurring around the UAV controller at Rancho Nuevo, Mexico (Photo: T. Wibbels, Binational Kemp's Ridley Recovery Program, using a DJI Phantom 3 Pro with integral camera at $30 \mathrm{~m}$ altitude) 

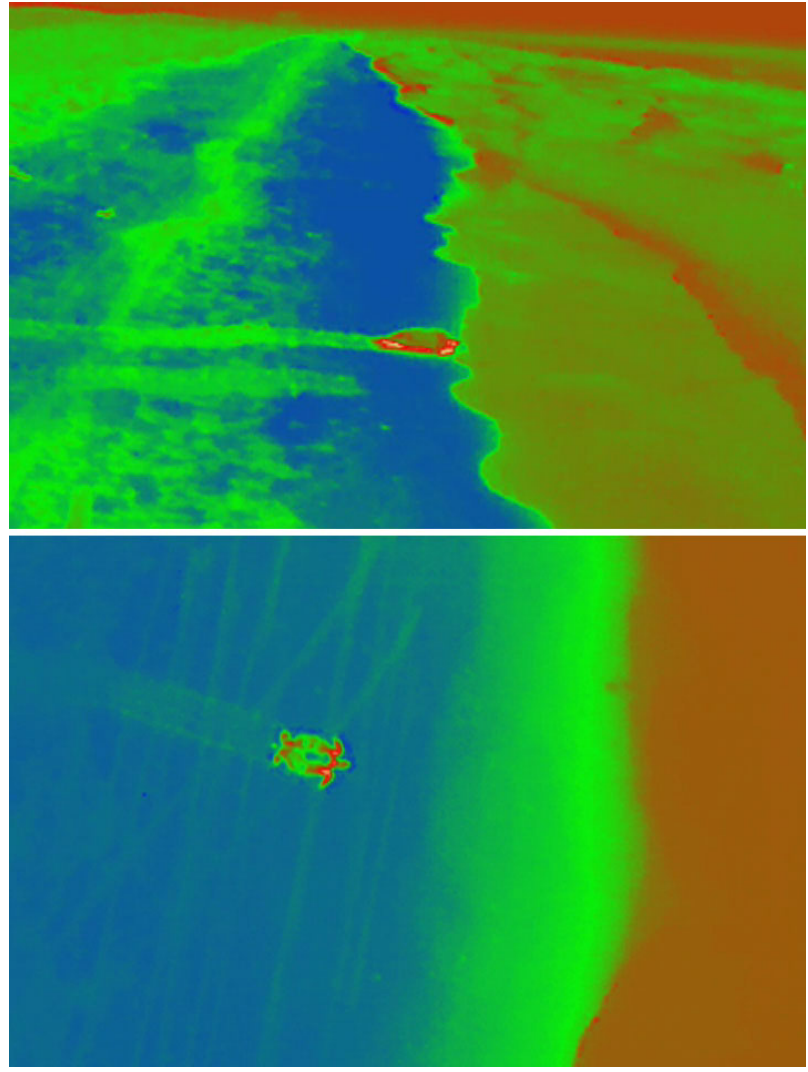

Fig. 2. Thermal images of a green turtle returning to the sea after nesting at Rancho Nuevo, Mexico. Blue: colder temperatures; red: warmer temperatures; green: intermediate temperatures (Photo: T. Wibbels, Binational Kemp's Ridley Recovery Program, using a DJI Inspire 1 with Zenmuse XT thermal camera at $10 \mathrm{~m}$ altitude)

factored in (e.g. Thomson et al. 2013, Seminoff et al. 2014). Nearshore turtle density estimations using UAVs as observation tools have started to appear in the literature (Sykora-Bodie et al. 2017)

Turtle behaviour. The utility of employing UAVs to monitor sea turtles in nearshore waters has been previously discussed (Bevan et al. 2015). Examples of their use have been to monitor courtship and mating behaviour (achieved by filming in 1080p video quality, flying $2 \mathrm{~km}$ parallel-to-shore transects; Bevan et al. 2016) and to record turtle behaviour around cleaning stations (Schofield et al. 2017b). By extension, under suitable conditions (i.e. shallow, clear water) other turtle behaviours such as post-nesting movements from nesting beaches, non-breeding turtleturtle interactions, predator avoidance, foraging behaviours and potential territorial behaviours can be studied. Systematic surveys would fly predetermined, repeatable transects with the capability to make the UAV hover at certain locations where study subjects were observed. UAVs are also useful in monitoring and tracking behaviour of hatchlings as they descend the beach immediately after hatching, and survivorship in nearshore waters. Use of inwater remotely operated vehicles (ROVs; Smolowitz et al. 2015) could supply complementary information to further enhance our understanding of sea turtle behaviour. Key issues are (1) to appropriately design sampling protocols with respect to the range of habitats or areas so that potential biases in results are understood; (2) to obtain adequate sample sizes; and (3) to confirm that the presence of the UAV does not alter the observed animals' behaviour.

Determination of operational sex ratios (OSR). Appropriately timed UAV surveys flown over the nearshore waters proximate to nesting beaches may be used to determine the OSR of a population. Timing is critical as turtles mate prior to the onset and during the early part of a breeding season (Godley et al. 2002, Hays et al. 2010). Adult (vs. juvenile) male and female turtles can be readily manually differentiated in high-resolution UAV footage recorded at a suitable altitude, as the tail of adult males extends well past the rear of the carapace (Bevan et al. 2016) (Fig. 4). This manual method has been successfully used to determine OSR by calculating the sex ratio of individuals from images recorded during transects (Schofield et al. 2017a); however, this assumes that males and females have an equal chance of being observed and correctly identified, and this potential bias would need to be addressed in the survey design.

\section{Habitats (nesting beaches and shallow-water foraging grounds)}

Two important habitats in sea turtle life history are nesting beaches, which are essential for all species to reproduce, and nearshore/shallow water habitats, as most sea turtle species forage on benthos. Habitat mapping, characterisation and modelling, often incorporated into geographical information systems (GIS), are critical for appropriate management of human activities which may affect sea turtle populations and their habitats (Lal et al. 2010), and in predicting likely changes to habitats under different climate change scenarios (Fuentes et al. 2011). Traditional mapping methods for nesting beaches include time-consuming ground-based surveys to produce standard mapping and elevation data, or rapid but costly aerial surveys that produce georeferenced photographic data (Mumby et al. 1999) and topography data if incorporating LiDAR (Long et al. 2011, Yamamoto et al. 2012) or SfM (Mancini et al. 2013). Likewise, shal- 


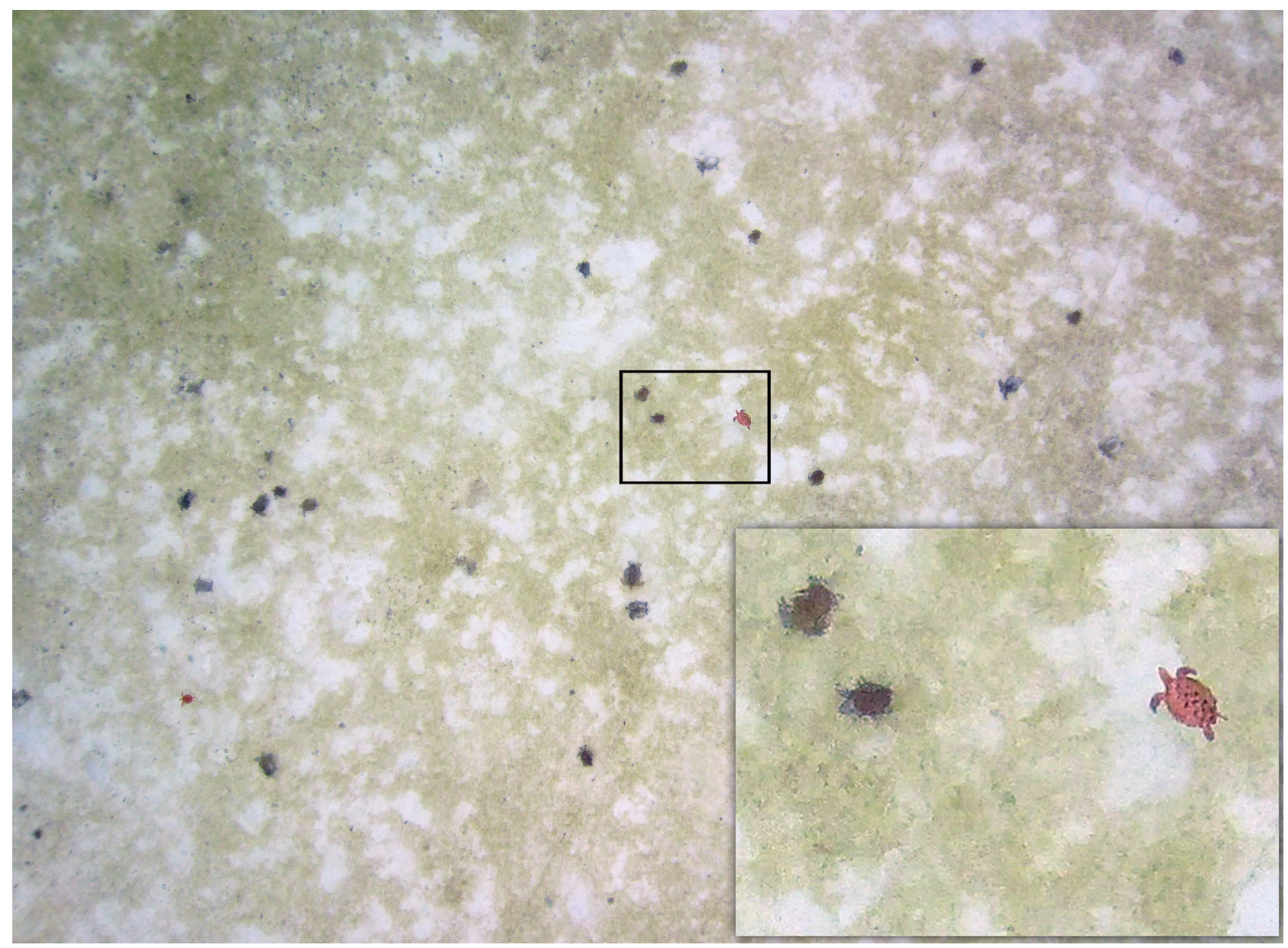

Fig. 3. Multiple sea turtles recorded within a single frame. High density green turtle foraging aggregation creates grazing gaps in seagrass beds at Derawan, Indonesia. Water depth: 2 m. (Photo: M. J. A. Christianen, using a senseFly Swinglet with a Canon IXUS $220 \mathrm{HS}$ at $20 \mathrm{~m}$ altitude)

low-water habitats can be mapped either from a boat using labour-intensive surveys to produce standard mapping data based on point or transect sampling (Hart et al. 2010) or via rapid and expensive aerial surveying that can produce georeferenced photographic data for relatively large areas (Sheppard et al. 1995, Chauvaud et al. 1998).

The rapid and cost-effective mapping and modelling capabilities of UAV-sourced data (see Ventura et al. 2016, 2017) have obvious application in the study of sea turtle habitats, but use processor-heavy software and necessitate high-specification IT infrastructure for efficient analysis.

Mapping habitats (terrestrial and shallow marine). Although more challenging in shallow marine habitats, detailed georectified orthomosaics (akin to maps in Google Earth) can be compiled from the high-resolution images and video captured by UAVs and incorporated into GIS. Orthomosaics from standard
UAV imagery may be produced with near $\mathrm{cm}$ accuracy (Fig. 5). These products far exceed the level of detail typical of satellite-derived or manned-aircraft imagery (Lathrop et al. 2006, Phinn et al. 2008, Wabnitz et al. 2008, Dekker et al. 2011). The low cost and simple logistics of undertaking UAV flights mean that these mapping exercises can be undertaken frequently, and essentially on demand in response to specific natural and anthropogenic environmental events such as storms or oil spills. The process is most effective when UAVs are flown repeatedly on predetermined autonomous missions. A single survey can provide a snapshot of the environment with habitats and plant species distribution characterised in GIS. However, with development of suitable computer applications (see Ventura et al. 2016, 2017), time-series imagery data resulting from repeated surveys can be used to monitor habitat change such as spread or dieback of certain types of marine plants, anthropogenic 


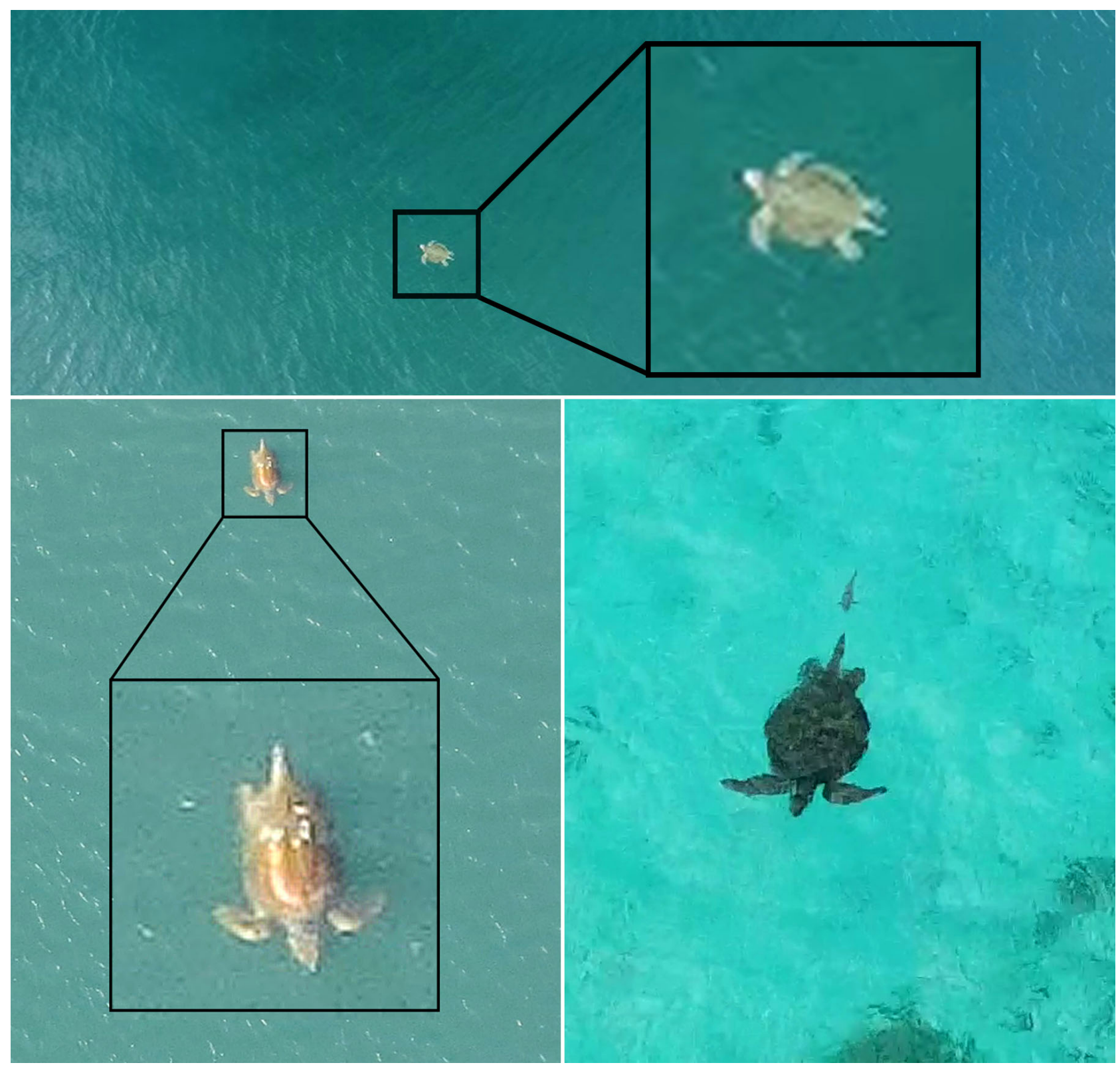

Fig. 4. Identification of sex of mature sea turtles from unmanned aerial vehicle (UAV) imagery possible through observation of the presence or absence of a longer, prehensile tail that extends past the rear of the carapace in adult and near-adult males. Upper image: Kemp's ridley sea turtle (Photo [from 1080p video]: T. Wibbels, Binational Kemp's Ridley Recovery Program). Lower left image: loggerhead turtle (Photo: L. Avens, using a senseFly eBee with a Canon IXUS camera at $65 \mathrm{~m}$ altitude; image was taken under authorization of NMFS ESA permit 16733 and US NPS permit CALO-2016-SCI-0002). Lower right image: green turtle (Photo [cropped]: R. D. Reina, using DJI Phantom 3 Pro with an integral 4K camera at 25 m altitude)

dune destruction, and coastal erosion. Such data could play a key role in evidence-based habitat conservation and management.

Beach profiling. Similar to the creation of 2D outputs from UAV data, accurate, georeferenced, 3D digital elevation models (DEMs) can be compiled from the high-resolution images. Sub-decimetre horizontal and vertical accuracy is possible with the appropriate use of ground control points and a real-time kinematic (RTK) or post-processing kinematic (PPK) system in tandem with high-overlap of recorded imagery (Long et al. 2016). The resultant DEMs can then be imported into GIS software for 3D analysis (Fig. 6). DEMs can also be used to model the visibility of light pollution on nesting beaches (Verutes et al. 2014) or to predict the effects of sea level rise on coastal (nesting) habitats 


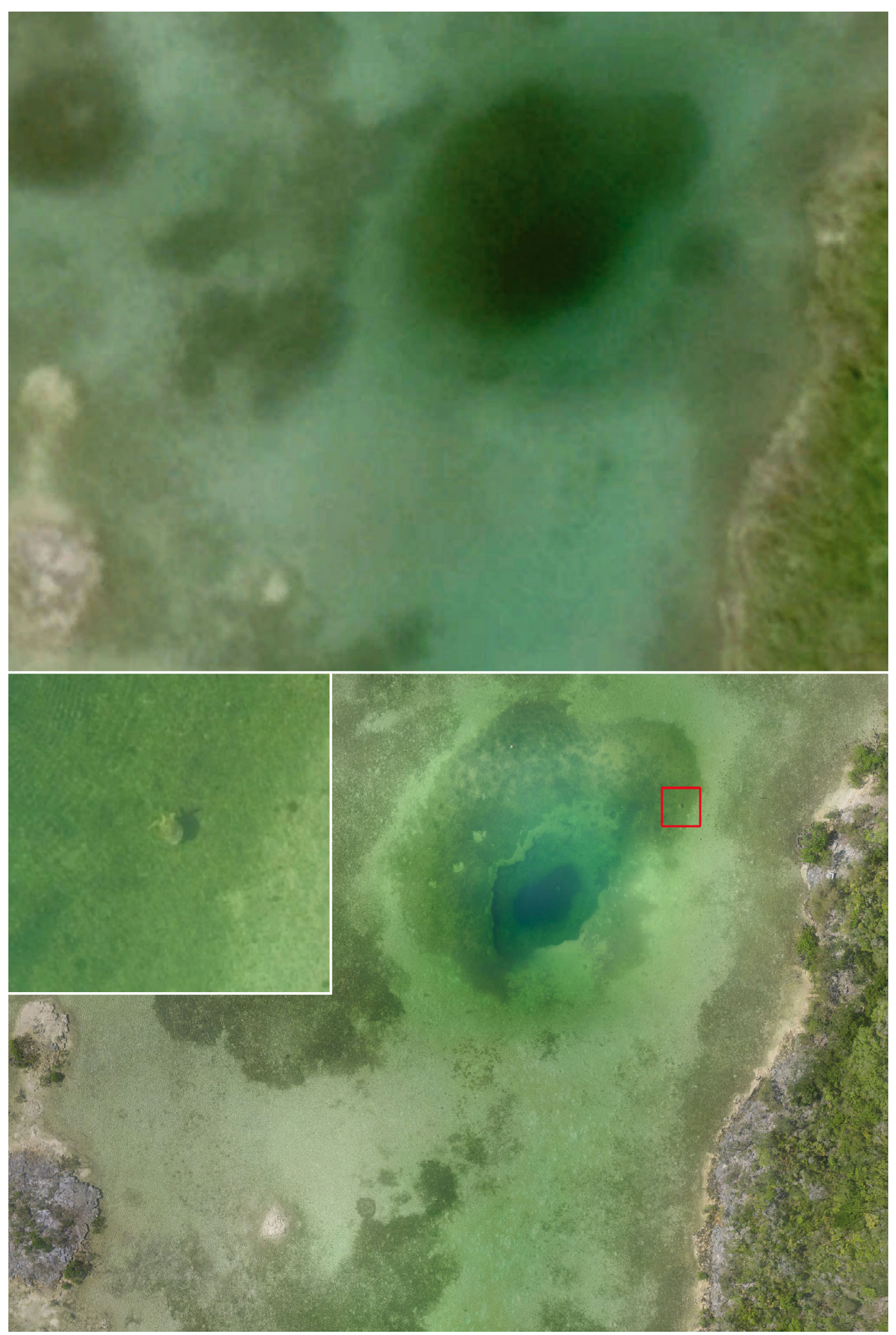

Fig. 5. Photogrammetric reconstruction of a section of tidal creek in the Bight of Old Robinson, Abaco, The Bahamas, with a $2 \mathrm{~cm}$ pixel resolution. Main images compare resolution between satellite (Google Earth; upper) and unmanned aerial vehicle (UAV; lower) derived imagery. Lower image inset displays the extreme detail that is readily possible using UAV data and photogrammetry (Image: E. R. Whitman, using a DJI Phantom 3 Advanced with a 2.7K HD camera at 30 m altitude) 

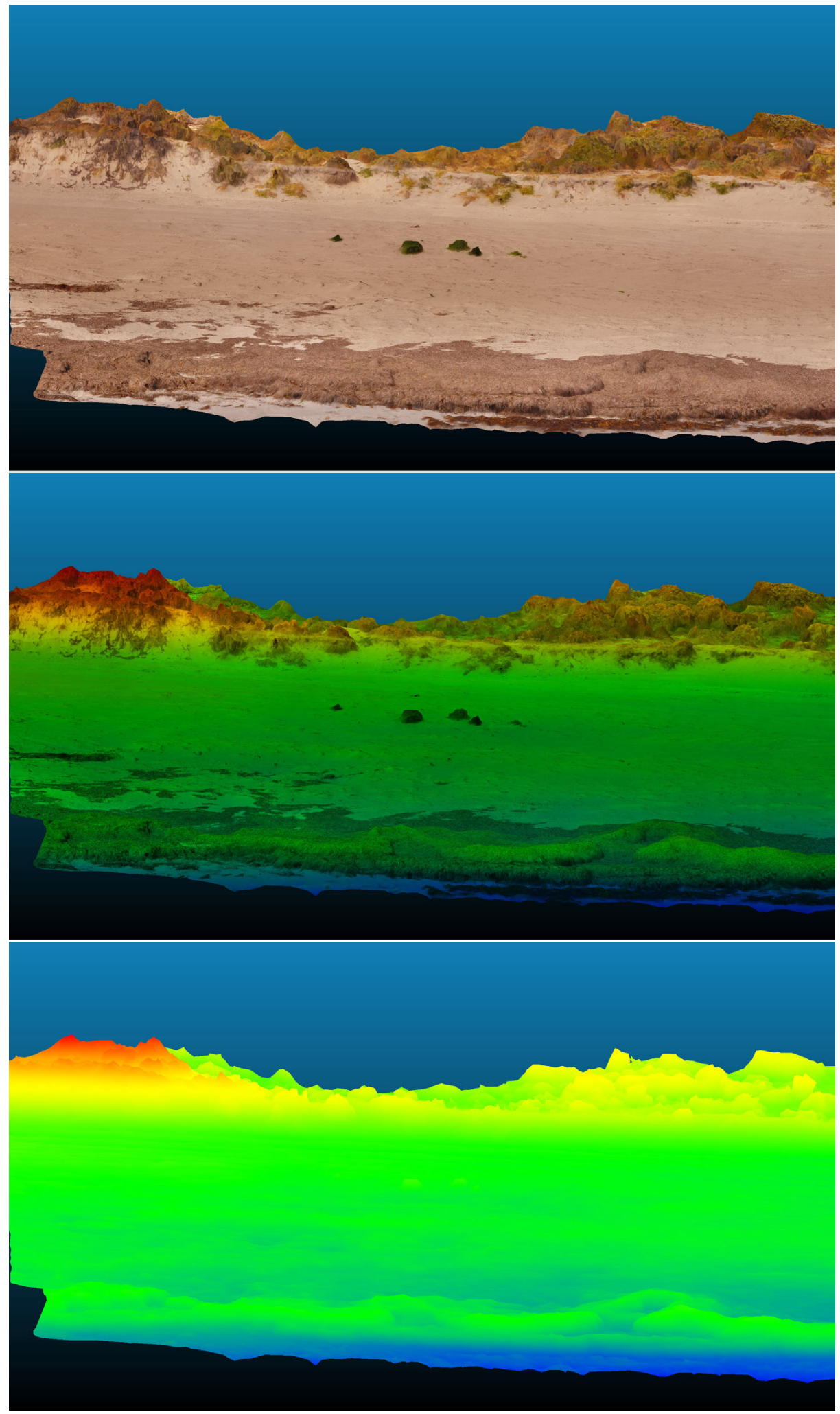

Fig. 6. Three-dimensional (3D) models, such as this one, can be used to predict the impact of sea level rise and potential light pollution problems on sea turtle nesting habitats (Image: K. Pendoley and R. Ryan). Upper image: 3D model of beach (strand line at the bottom) with texture mesh. Middle image: same model with height data colour ramp overlay. Lower image: same model showing only height data. Colour ramp runs from reds at highest elevation to blue for lowest elevation 
(e.g. Baker et al. 2006). UAVs have also been used successfully to assess wave run-up on beaches (Casella et al. 2014), which may be another valuable approach to understand how existing nests may be affected by storms or short-term sea level anomalies (e.g. Theuerkauf et al. 2014).

\section{Surveillance for anthropogenic influence}

Other, more applied uses of UASs in turtle conservation are possible. Rather than simply becoming an extension or improvement of established research tools, they can be used in direct-action conservation monitoring and enforcement measures, as in other terrestrial situations. In the management context, UAV surveys may be useful in at least 3 ways (see Mulero-Pázmány et al. 2014): (1) as surveillance platforms where UAVs patrol areas to detect illegal or unpermitted activities; (2) as enforcement tools that can loiter over potential violators and guide enforcement efforts and (3) as a behaviour modification tool, where consistent but unpredictable aerial surveillance reduces illegal activities. It should be noted here that there are outstanding questions of privacy and ethics associated with using UAVs in the surveillance of human activities (Sandbrook 2015), which we address briefly at the end of this paper.

Specifically, for marine turtle conservation, both still and video imagery from UAVs can be used in surveillance monitoring as follows:

Marine/fisheries monitoring. UAVs recording highdefinition video and images make powerful tools in fisheries monitoring by enhancing the effectiveness of alternative-platform observer programmes (e.g. Byrd et al. 2016) and complement other methods of electronic visual monitoring (Bicknell et al. 2016). UAVs flown over marine protected areas and over and around vessels under surveillance could supply live data on the fishing operations. They would be capable of identifying whether a vessel is fishing, its geographic coordinates, what gears are being used and, depending on the vessel and the UAV's sensor capabilities, it could potentially identify the target species, bycatch and treatment of bycaught protected species such as sea turtles (Fig. 7). Real-time evidence thus remotely gathered could inform management agencies whether intervention is required and could guide enforcement assets to the site. Georeferenced and time-stamped images and video obtained during the monitoring would act as a permanent record of infractions such as illegal take and violation of protected area boundaries.
Terrestrial enforcement. Using UASs to autonomously identify and track illegal hunting activity is already being explored for endangered wildlife; the rhinoceros is a notable example (Olivares-Mendez et al. 2015). This approach can be adapted to localisation and tracking of egg and turtle harvesters at locations where these activities are restricted or illegal. In this instance, UAVs could be flown along preprogrammed routes with FPV enabled so that manual control can be gained if suspicious activity is observed. Standard visual imagery for diurnal surveillance should be supplemented with thermal imagery for nocturnal surveillance where the heat signature of the human subject would clearly stand out from the background, which may be dense forest or bushes, thus simplifying tracking and apprehension of the subject (Fig. 7; https://youtu.be/biHmI-YvwlI)

Effects of tourism on behaviour. Often drawn to similar coastal habitats, humans use sandy beaches and coastal waters for recreation, while turtles use these areas during multiple life stages for nesting, mating and grazing. Turtles themselves often become an attraction, drawing tourists to visit their coastal habitats (Wilson \& Tisdell 2001). Tourism activities such as boating can produce noise affecting turtle behaviour in coastal mating, nesting and foraging habitats (Samuel et al. 2005, Eckert 2012), and activities such as diving, snorkelling and use of non-motorized vessels can affect activity budgets, at least on a short timescale (Hayes 2016). UASs have the potential to monitor these activities and their effects on sea turtle behaviour. While ethical concerns exist regarding the privacy of tourists, data from UAVs on human inwater use, turtle behaviours (at least surfacing) and also turtle distributions would provide insight for management agencies as eco-tourism increases.

\section{Promoting awareness for conservation}

A further use of UASs for sea turtle conservation simply relies on the potential for UAVs to record visually impressive stills and video footage that can be used to capture interest and raise conservation awareness, and to support the mandated broader impact requirements of many research programmes. Aerial viewpoints and sweeping scenes that UAVs can shoot in high-definition video create impactful, cinematic visuals to inspire, educate and instill the viewer with a greater appreciation for the natural world.

Examples of circumstances where aerial imagery of sea turtles are of tangible benefit to outreach and engagement (viewing statistics as of 31 October, 

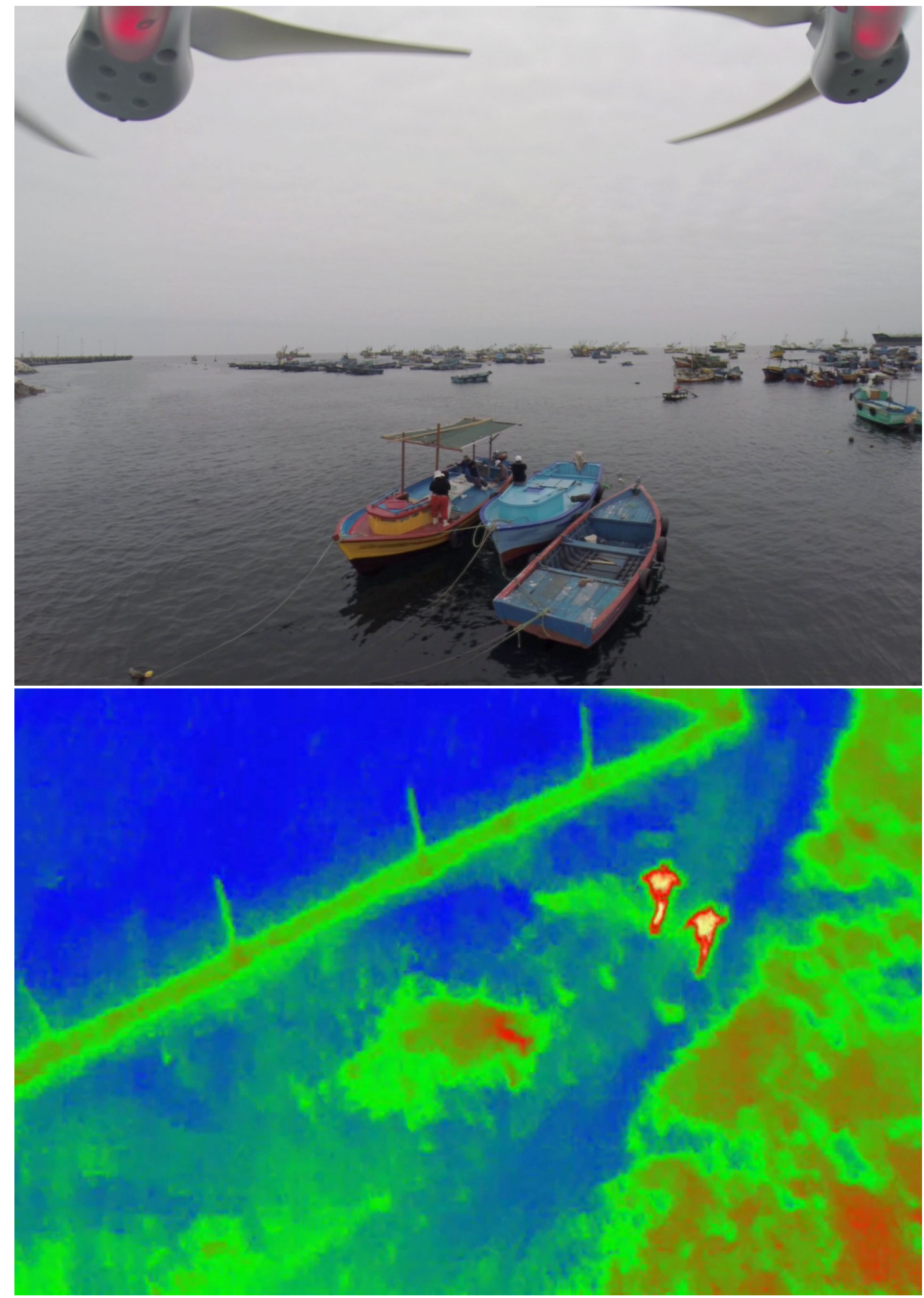

Fig. 7. Unmanned aerial vehicle (UAV) imagery used for remote observation and surveillance. Upper image: inspecting fishing boats. The arms and propellers of the UAV are visible in the image as the UAV was in a banking manoeuvre (Photo: J. C. Mangel, using a DJI Phantom 2 with GoPro Hero3+ Black edition at $5 \mathrm{~m}$ altitude). Lower image: thermal image of 2 people (in this case, project personnel) running past the main sea turtle egg hatchery in the centre of Rancho Nuevo, Mexico, demonstrating the potential for nocturnal UAV surveillance operations (Photo: T. Wibbels, Binational Kemp's Ridley Recovery Program, using a DJI Inspire 1 with Zenmuse XT thermal camera at $30 \mathrm{~m}$ altitude) 
2017) include (1) behaviour and movements of turtles in clear, shallow water habitats (https://vimeo.com/ $175689526 ;>16000$ views) or on a nesting beach (https://youtu.be/RPxPIxN2VpQ; $>9800$ views); (2) release of a turtle back to the sea after human intervention, e.g. rescue after illegal capture, attachment of a satellite transmitter, post-rehabilitation release etc. (e.g. https://youtu.be/i3LQYV7_aD8 >10000 views); (3) field researchers working, either with turtles in a boat or with a nest on a beach; (4) flights over daytime nesting events - especially arribadas (mass nesting events where several hundred to several thousand turtles come ashore to nest at once) (https:// youtu.be/mY29SNy0Y9Y >44000 views; note this is footage from a microlight aircraft and similar UAV footage should be of better quality); and (5) footage of a turtle rescue/rehabilitation centre showing turtles in pools (e.g. https://vimeo.com/204257624).

\section{DISCUSSION}

\section{An eye to the future}

Technological advances in hardware and software capabilities will improve the efficacy of existing conservation methods that can be applied with current equipment and at reduced cost. They may also lead to novel, currently untenable applications.

\section{Improved hardware capabilities: range extension for affordable UAVs}

Coastal and marine environments present unique operating challenges for UAVs, and the potential for platform loss due to water landings or corrosion is ever-present. Fortunately, an increasing number of 'waterproof drones' are now reaching the consumer market (e.g. www.dronesglobe.com/guide/ waterproof/), and potential users may benefit from the added operational flexibility and safety afforded by these platforms.

Improvements in battery technology, hydrogen fuel cells and solar energy generation will extend flight times and distances for UAVs, thus bringing the capabilities of larger, more expensive UAVs into the reach of conservation scientists and practitioners. The possibility of persistent flights could drastically increase the effectiveness of monitoring and surveillance programs where an immediate response to insidious threats is required, such as the prevention of illegal take.
Incorporating the use of cellular networks to trigger autonomous UAV missions or remotely fly FPV is already in development (https://blog.adafruit.com/ 2013/08/23/sky-drone-fpv-uses-3g4g-cell-networkto-provide-long-range-rc/). If successful, this will reduce the need to visit remote field sites in monitoring programmes (with the caveat that there is cellular network coverage), thus saving resources that can be used on other initiatives.

\section{Improved software capabilities: automation and intelligent systems}

Development of automation of data interpretation, such as shape and texture recognition algorithms (often referred to collectively as computer vision techniques), would obviate the need to manually review hours of video and many still images, and could revolutionise sea turtle monitoring. Such systems are already in place for identifying large land animals in surveys (Lhoest et al. 2015, van Gemert et al. 2015, Gonzalez et al. 2016) and enumerating colonial animals (Seymour et al. 2017). Systems that seek to automatically detect sea turtle nesting activity such as the MiSHELL Drones project (www.kashmirworld foundation.org/mishell) or automatically identify and map turtles and other taxa in shallow water habitats such as the SEMMADRONE project (www.slideshare .net/GwnalDUCLOS/ists36-sea-turtles-semiautomaticmapping-technics) are under development, and could lead to a step change in conservation practices. Further, the capacity for on-board processing and identification of turtles would be further advanced if the flight pattern of the UAV could be autonomously altered to more closely investigate objects for which identification is unclear. In these situations, the presence of targets of interest is established via on-board computational systems, and only then are the details of detections transmitted to the user. This approach can reduce energy and bandwidth consumption and analyst time, and provide for rapid communication of important information to humans.

\section{Novel uses of UASs: non-visual information acquisition and relay}

Radio- or archival-tagged sea turtles in restricted habitats could be located from on-board UAVmounted receivers. The movement of the UAV, monitoring the direction of origin of a signal, would be able to generate location hotspots for the tracked 
individuals. Turtles remain submerged for extended periods and only surface intermittently; thus, the chances of detecting signals from sea turtles would be challenging but increasingly likely with lengthening flight times or where multiple turtles are tracked within restricted areas such as coastal foraging areas. This technique has proven useful for terrestrial animals in inaccessible terrain (dos Santos et al. 2014) and consequently has immediate potential for the repeated location of study animals on nesting beaches either within or among nesting seasons.

Taking the theme of UAVs automatically locating subjects to the next logical step leads to the acquisition and exchange of data between turtle-mounted data logging devices and the UAV, essentially using the remote aircraft as a data mule. Archival tags with 2-way communication capabilities, deployed on a variety of taxa, could send data to the UAVs that is then downloaded at the end of the mission. Two-way communication is beneficial as the archival tag would track what data has been made available to (and received by) the researcher, who could then update the tag's programming if required. The turtle in effect acts as a mobile data-gathering and -sharing node, relaying behaviour, environment and, potentially, video data.

An extension of the above scenario would use UAVs to visit distributed data-capture points (base stations) on nesting beaches and buoys in marine habitats to retrieve tracking data that have been collected from tagged animals (Tavakoli et al. 2016). Here, the flight limitations of the UAVs are less restrictive as they only need to be deployed on missions to known locations for data retrieval as opposed to covering a larger expanse of territory with no certainty of encountering a study animal. A number of studies have explored the use of UAVs as data mules to facilitate communication of data across networks of sensors (e.g. Sayyed et al. 2015, Wang et al. 2015).

\section{Legal and ethical implications}

Technological advances are regularly increasing the capabilities and safety of consumer-grade UAVs. Most platforms now have altitude- (and for multirotors, horizontal-) position stabilisation and 'returnto-home' capabilities. Several new platforms employ optical or ultrasonic sensors for obstacle sensing and avoidance capabilities (e.g. Phantom 4 Pro; www.dji. com). However, these developments are often negated through user misuse and unfettered access to UAV purchasing, so that UAV use is outpacing the development of adequate regulatory frameworks. The low barriers to acquiring a UAV and their potential for negative impacts on privacy, security and safety - especially for manned aviation - prescribe that strict regulations be set for their operation. Regulations may differ with the status of the pilot (hobbyist, commercial, or non-hobbyist such as academic, research use, etc.), the size of the UAV and the area of operation (Cracknell 2017). Editorial comments in the International Journal of Remote Sensing cited the tendency of academics to merge their hobbies and their work, and stressed that this will no longer be possible under the liability, safety and accountability standards of evolving UAV legislation (Anon 2017). An important consideration for those using UAVs for research and conservation is the outlet for their products, as institutions, agencies and journals may begin to require the same due diligence be paid to UAV legislation that is afforded to species permits and animal care and use compliance. Unfortunately, conscientious users are potentially being hindered by legislative efforts to control UAV use (Linchant et al. 2015, Vincent et al. 2015).

National and state UAV regulations are not static instruments, but are rapidly evolving and often becoming more complex and restrictive. In the USA, issues such as the requirement for registration of UAVs are often disconnected, and many individual states are implementing their own laws regarding UAV use that may conflict with federal rules and regulations. The European Union issued 'prototype' regulations in August 2016 that call for registration of all UAVs above $250 \mathrm{~g}$ and all UAV operators, and restrict flights to visual-line-of-sight (VLOS; 'the remote pilot maintains continuous unobstructed and unaided visual contact with the UA, allowing the remote pilot to monitor the flight path of the UA in relation to other aircraft, persons, and obstacles, for the purpose of maintaining separation from them and avoiding collisions.' EASA 2016, p. 5), none of which were previously in place in several European countries. Before initiating a UAS project, it is imperative that the operator learns the current UAV regulations of the country in which the fieldwork will take place and subsequently flies within the relevant national regulations. Information is normally located on the authority's web page (e.g. EU: https://www.easa. europa.eu/easa-and-you/civil-drones-rpas\#group-easarelated-content; USA: https://www.faa.gov/uas/; Australia: https://www.casa.gov.au/aircraft/landing-page/ flying-drones-australia). Users considering traveling with or importing UAVs may also be impacted by changing import/export regulations and tariffs, and 
multiple governing agencies may need to be notified prior to travel (Watts et al. 2012, Cerna 2016, Department of State 2017).

In addition to legal issues and health and safety concerns, the social implications of using UASs for research need to be addressed (Clarke 2014). In an extensive review, Sandbrook (2015) highlighted the ethical questions around data acquisition where images of identifiable people, or the resources they care about, are collected and may be used against those people. He also raises the need for transparency in UAV operations to minimise pervasiveness of hearsay and rumour that may negatively affect operations through distrust, objections and potential hostile actions. Until we have empirical evidence of the impact of UAVs on the social aspects of research and conservation, site-specific self-regulation and outreach are central to the success of projects employing UAVs for data collection. In fact, while regulations and general information on the social perception of UAVs can guide their use, continued efforts to build positive relationships between conservationists or researchers and local communities may be the only way to ensure project success at any specific site.

Ethical and welfare issues concerning possible interactions between the study animals and other wildlife and the UAV also need to be considered. For populations under legal protection due to their conservation status, permits are often required to conduct research activities such as surveys that have the potential to affect target animals, and these effects must be minimised. While UAVs may be deployed in lieu of techniques that cause significant disturbance or harm to animals (e.g. walking through colonies, approaching animals with boats or flying over them in loud aircraft), we must consider how these new technologies are perceived by wildlife. As with most observational techniques, there is ample opportunity for mis-application that can cause unintended disturbance to target and non-target species. These situations may have negative implications for the animals we study and also for the quality of data collected. As such, for sea turtles, there is a need to establish if and how they react to UAVs when deployed in both terrestrial and at-sea applications. At least 2 areas of concern are initially apparent: (1) whether marine turtles are disturbed by the sounds that UAVs produce and (2) whether marine turtles perceive the shadow or silhouette of a UAV in flight as a threat. The hearing capabilities of turtles are relatively well studied (see Piniak et al. 2012) and there have been some efforts to quantify sounds produced by UAVs to assess

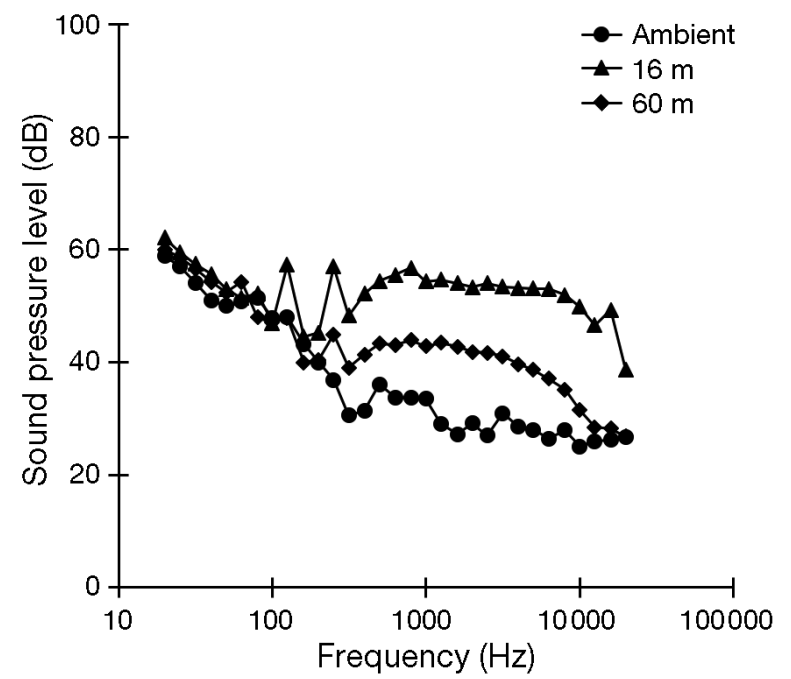

Fig. 8. Received 1/3 octave band calibrated sound equivalent levels for a Mikrokopter hexacopter flown at 16 and $60 \mathrm{~m}$. Sound levels recorded using a calibrated UMIK-1 connected to an Apple iPad running Faber Acoustical Sound Meter App (Kardous \& Shaw 2014)

their disturbance on marine wildlife. For example, Christiansen et al. (2016) assessed the underwater sounds of 2 small UAVs in relation to the hearing of large whales. They concluded that UAV sounds may be detectable by large whales, but that the underwater noise effect is small, even for animals close to the water surface. In addition, an ever-increasing number of UAVs have been assessed for in-air sound levels. Fig. 8, for example, displays in-air calibrated equivalent sound levels of a Mikrokopter hexacopter (www.mikrokopter.de) during flights at 16 and $60 \mathrm{~m}$ altitude. In general, hard-shell turtle species can detect frequencies of 100 to $1000 \mathrm{~Hz}$, with peak sensitivity between 100 and $500 \mathrm{~Hz}$ at received sound pressure levels above $80 \mathrm{~dB}$ re $20 \mu \mathrm{Pa}$ (Piniak et al. 2012). Fig. 8 illustrates that received levels did not exceed $80 \mathrm{~dB}$ re $20 \mu \mathrm{Pa}$ at either altitude for this aircraft, and these results suggest that marine turtles are unlikely to hear them during regular operations. Marine turtles may perceive UAVs visually, either through shadows thrown onto the local benthos in shallow waters or by direct observation of the silhouette of the aircraft as it flies over. This may be especially true for delta-wing type aircraft, which more closely resemble predatory birds that may attack them (especially as hatchlings), than canardshaped aircraft or the more box-like shape of multirotor aircraft (Fig. 9). Bevan et al. (2015) did not observe any response by adult and hatchling Kemp's ridley sea turtles to rotorcraft during overflights. However, more research is required to understand if 

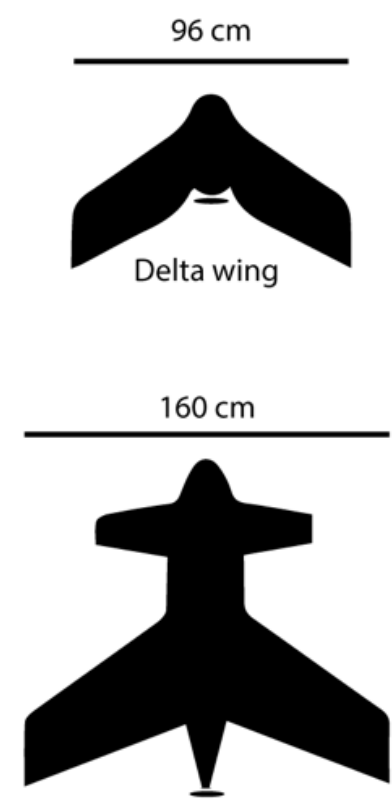

Canard airframe

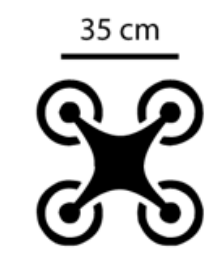

Multicopter

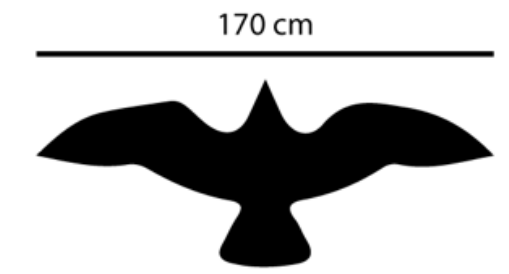

Great black-backed gull

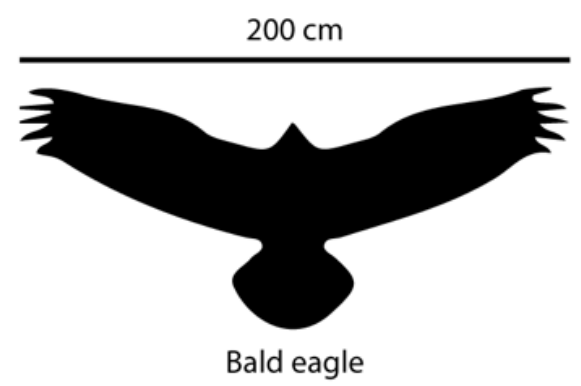

Fig. 9. Silhouettes and wingspans of several unmanned aerial vehicle (UAV) airframes in comparison to typical North American predatory birds and how marine turtles perceive UAVs during flight, and whether any adverse effects may result from overflights.

\section{CONCLUSIONS}

Sea turtle researchers and managers need to ensure they are correctly equipped to maximise the usefulness of results and draw benefits from new data acquisition capabilities facilitated by use of UAVs. Choice of UAV hardware and survey design appropriate to the research needs will generate data that can transform our understanding of sea turtle ecology and population dynamics. However, despite great potential, UASs cannot fully replace all ground-based fieldwork and surveys. As stipulated, suitable environmental field conditions are required for effective use of UAVs, and legislative restrictions (e.g. line-of-sight flight distance limitations) may mean ground-based beach surveys are more effective in certain areas. UAV use is obviously not applicable to research programmes that require physical sampling of the study site or organisms.

In April 2017, at the $37^{\text {th }}$ Annual Symposium of Sea Turtle Biology and Conservation, 53 researchers from 42 institutions in 12 countries (many co-authors here) attended a workshop on the use of UAVs for sea turtle conservation to gain a grounding in the field or share their UAS research experiences. The workshop covered essential considerations for starting out with UAS research, novel uses of UAVs as data-gathering tools and key challenges facing practitioners in the field. Partcipants concluded that successful research programs using UAVs need careful planning, preparation and incremental development, and that flying conditions and provision of sufficient computer storage and processing capabilities are key challenges that need to be addressed (Rees et al. 2017). The consensus, with which we concur, was that UAVs provide an exciting opportunity to enhance our study and protection of sea turtles, provided their benefits, limitations and uses are well understood. There is an ever-increasing cadre of research and management groups using UAVs to study sea turtle ecology. It is clearly a realm set to grow.

Acknowledgements. Any use of trade, firm, or product names is for descriptive purposes only and does not imply endorsement by the US Government. This is contribution \#80 from the Marine Education and Research Center in the Institute of Water and Environment at Florida International University. The authors acknowledge the constructive input of 3 anonymous referees. 


\section{LITERATURE CITED}

Afán I, Navarro J, Cardador L, Ramírez F and others (2014) Foraging movements and habitat niche of two closely related seabirds breeding in sympatry. Mar Biol 161: 657-668

Anderson K, Gaston KJ (2013) Lightweight unmanned aerial vehicles will revolutionize spatial ecology. Front Ecol Environ 11:138-146

Anon (2017) Unmanned aerial vehicles for environmental applications. Int J Remote Sens 38:2029-2036

Baker JD, Littnan C, Johnston DW (2006) Potential effects of sea level rise on the terrestrial habitats of endangered and endemic megafauna in the northwestern Hawaiian Islands. Endang Species Res 2:21-30

Ballorain K, Bourjea J, Ciccione S, Kato A and others (2013) Seasonal diving behaviour and feeding rhythms of green turtles at Mayotte Island. Mar Ecol Prog Ser 483:289-302

Ballorain K, Wagner J, Ciccione S (2016) Drone technology used for foraging sea turtle surveys. In: Belskis L, Frey A, Jensen M, LeRoux R, Stewart K (compilers) Proc 34 ${ }^{\text {th }}$ Annual Symposium Sea Turtle Biology and Conservation. NOAA Tech Memo NMFS-SEFSC-701

Bell CD, Blumenthal JM, Austin TJ, Ebanks-Petrie G, Broderick AC, Godley BJ (2008) Harnessing recreational divers for the collection of sea turtle data around the Cayman Islands. Tour Mar Environ 5:245-257

Bevan E, Wibbels T, Najera BM, Martinez MA and others (2015) Unmanned aerial vehicles (UAVs) for monitoring sea turtles in near-shore waters. Mar Turtle Newsl 145: 19-22

Bevan E, Wibbels T, Navarro E, Rosas M and others (2016) Using unmanned aerial vehicle (UAV) technology for locating, identifying, and monitoring courtship and mating behavior in the green turtle (Chelonia mydas). Herpetol Rev 47:27-32

Bicknell AWJ, Godley BJ, Sheehan EV, Votier SC, Witt MJ (2016) Camera technology for monitoring marine biodiversity and human impact. Front Ecol Environ 14: 424-432

Bolten AB (2003) Variation in sea turtle life history patterns: neritic vs. oceanic developmental stages. In: Lutz PL, Musick JA, Wyneken J (eds) The biology of sea turtles, Vol 2. CRC Press, Boca Raton, FL, p 243-257

*Bourjea J, Dalleau M, Derville S, Beudard F and others (2015) Seasonality, abundance, and fifteen-year trend in green turtle nesting activity at Itsamia, Moheli, Comoros. Endang Species Res 27:265-276

Bresette MJ, Witherington BE, Herren RM, Bagley DA and others (2010) Size-class partitioning and herding in a foraging group of green turtles Chelonia mydas. Endang Species Res 9:105-116

Brooke S, Graham D, Jacobs T, Littnan C, Manuel M, O'Conner R (2015) Testing marine conservation applications of unmanned aerial systems (UAS) in a remote marine protected area. J Unmanned Vehicle Syst 3:237-251

Bryson M, Johnson-Roberson M, Murphy RJ, Bongiorno D (2013) Kite aerial photography for low-cost, ultra-high spatial resolution multi-spectral mapping of intertidal landscapes. PLOS ONE 8:e73550

Byrd BL, Goshe LR, Kolmeyer T, Hohn AA (2016) Sea turtle bycatch in the large-mesh gillnet flounder fishery in Carteret County, North Carolina, USA, June-November 2009. J N Carolina Acad Sci 132:10-24

Casella E, Rovere A, Pedroncini A, Mucerino L and others
(2014) Study of wave runup using numerical models and low-altitude aerial photogrammetry: a tool for coastal management. Estuar Coast Shelf Sci 149:160-167

Cerna I (2016) The UAVs in international trade - current state of play and regulatory issues. In: Cerna I (ed) Central and eastern Europe in the changing business environment: Proc $16^{\text {th }}$ International Joint Conference. Oeconomica Publishing House, Prague, p 49-59

* Chabot D, Bird DM (2015) Wildlife research and management methods in the 21st century: Where do unmanned aircraft fit in? J Unmanned Vehicle Syst 3:137-155

Chassagneux A, Jean C, Bourjea J, Ciccione S (2013) Unraveling behavioral patterns of foraging hawksbill and green turtles using photo-identification. Mar Turtle Newsl 137:1-5

* Chauvaud S, Bouchon C, Maniere R (1998) Remote sensing techniques adapted to high resolution mapping of tropical coastal marine ecosystems (coral reefs, seagrass beds and mangrove). Int J Remote Sens 19:3625-3639

Christiansen F, Rojano-Doñate L, Madsen PT, Bejder L (2016) Noise levels of multi-rotor unmanned aerial vehicles with implications for potential underwater impacts on marine mammals. Front Mar Sci 3:277

Clarke R (2014) Understanding the drone epidemic. Comput Law Secur Rev 30:230-246

Cracknell AP (2017) UAVs: regulations and law enforcement. Int J Remote Sens 38:3054-3067

* Dandois JP, Ellis EC (2010) Remote sensing of vegetation structure using computer vision. Remote Sens 2: 1157-1176

พDeBell L, Anderson K, Brazier RE, King N, Jones L (2016) Water resource management at catchment scales using lightweight UAVs: current capabilities and future perspectives. J Unmanned Veh Syst 4:7-30

*Dekker AG, Phinn SR, Anstee J, Bissett J and others (2011) Intercomparison of shallow water bathymetry, hydrooptics, and benthos mapping techniques in Australian and Caribbean coastal environments. Limnol Oceanogr Methods 9:396-425

* Department of State (2017) The international traffic in arms regulations (ITAR). US Department of State, Directorate of Defense Trade Controls, Washington, DC. www.pmddtc.state.gov/regulations_laws/itar.html (accessed 23 Oct 2017)

* do Amaral KB, Alvares DJ, Heinzelmann L, Borges-Martins M, Siciliano S, Moreno IB (2015) Ecological niche modeling of Stenella dolphins (Cetartiodactyla: Delphinidae) in the southwestern Atlantic Ocean. J Exp Mar Biol Ecol 472:166-179

* dos Santos GAM, Barnes Z, Lo E, Ritoper B and others (2014) Small unmanned aerial vehicle system for wildlife radio collar tracking. In: IEEE $11^{\text {th }}$ International Conference on mobile ad hoc and sensor systems (MASS). http:// ieeexplore.ieee.org/abstract/document/7035779/

*Doon JN, Fromentin JM, Hanke AR, Arrizabalaga H and others (2016) Habitat suitability of the Atlantic bluefin tuna by size class: an ecological niche approach. Prog Oceanogr 142:30-46

* Duffy JP, Anderson K (2016) A 21st-century renaissance of kites as platforms for proximal sensing. Prog Phys Geogr 40:352-361

EASA (European Aviation Safety Agency) (2016) ‘Prototype' commission regulation on unmanned aircraft operations. European Aviation Safety Agency, Cologne. https:// www.easa.europa.eu/system/files/dfu/UAS\%20Prototype 
\%20Regulation\%20final.pdf (accessed 15 Mar 2017)

Eckert S (2012) Underwater hearing sensitivity of the leatherback sea turtle (Dermochelys coriacea): assessing the potential effect of anthropogenic noise. Bureau of Ocean Energy Management, Herndon, VA. www.data.boem. gov/PI/PDFImages/ESPIS/5/5279.pdf (accessed 24 May 2017)

Eguchi T, Gerrodette T, Pitman RL, Seminoff JA, Dutton PH (2007) At-sea density and abundance estimates of the olive ridley turtle Lepidochelys olivacea in the eastern tropical Pacific. Endang Species Res 3:191-203

Evans IJ, Jones TH, Pang K, Evans MN, Saimin S, Goossens B (2015) Use of drone technology as a tool for behavioral research: a case study of crocodilian nesting. Herpetol Conserv Biol 10:90-98

Fuentes MMPB, Limpus CJ, Hamann M (2011) Vulnerability of sea turtle nesting grounds to climate change. Glob Change Biol 17:140-153

Fuentes MMPB, Bell I, Hagihara R, Hamann M and others (2015) Improving in-water estimates of marine turtle abundance by adjusting aerial survey counts for perception and availability biases. J Exp Mar Biol Ecol 471: 77-83

Godley BJ, Broderick AC, Frauenstein R, Glen F, Hays GC (2002) Reproductive seasonality and sexual dimorphism in green turtles. Mar Ecol Prog Ser 226:125-133

* Goebel ME, Perryman WL, Hinke JT, Krause DJ, Hann NA, Gardner S, LeRoi DJ (2015) A small unmanned aerial system for estimating abundance and size of Antarctic predators. Polar Biol 38:619-630

Gonzalez LF, Montes GA, Puig E, Johnson S, Mengersen K, Gaston KJ (2016) Unmanned aerial vehicles (UAVs) and artificial intelligence revolutionizing wildlife monitoring and conservation. Sensors (Basel) 16:97

Hart KM, Zawada DG, Fujisaki I, Lidz BH (2010) Inter-nesting habitat-use patterns of loggerhead sea turtles: enhancing satellite tracking with benthic mapping. Aquat Biol 11:77-90

Hayes C (2016) Does recreational diving alter hawksbill sea turtle foraging behavior? Results from a marine protected area, Honduras. The Research and Scholarship Symposium, 20 April 2015, Cedarville, OH. http// digitalcommons.cedarville.edu

Hays GC, Fossette S, Katselidis KA, Schofield G, Gravenor MB (2010) Breeding periodicity for male sea turtles, operational sex ratios, and implications in the face of climate change. Conserv Biol 24:1636-1643

Hodgson A, Kelly N, Peel D (2013) Unmanned aerial vehicles (UAVs) for surveying marine fauna: a dugong case study. PLOS ONE 8:e79556

Jang SW, Lee SK, Kim DH, Chung YH, Yoon HJ (2015) Application of remote environmental monitoring technique to efficient management of beach litter. Int $\mathrm{J} \mathrm{u}$ - eServ Sci Technol 8:357-368

Jean C, Ciccione S, Ballorain K, Georges J, Bourjea J (2010) Ultralight aircraft surveys reveal marine turtle population increases along the west coast of Reunion Island. Oryx 44:223-229

Jensen A, Neilson B, McKee M, Chen Y (2012) Thermal remote sensing with an autonomous unmanned aerial remote sensing platform for surface stream temperatures. In: Proc 2012 IEEE International Geoscience and Remote Sensing Symposium, Munich, Germany, 22-27 July 2012. IEEE Computer Society, Washington, DC, p 5049-5052. http://ieeexplore.ieee.org/document/6352476
Jones GP, Pearlstine LG, Percival HF (2006) An assessment of small unmanned aerial vehicles for wildlife research. Wildl Soc Bull 34:750-758

Kardous CA, Shaw PB (2014) Evaluation of smartphone sound measurement applications. J Acoust Soc Am 135: EL186-EL192

* Kiszka J, Mourier J, Gastich K, Heithaus MR (2016) Using unmanned aerial vehicles (UAVs) to investigate shark and ray densities in a shallow coral lagoon. Mar Ecol Prog Ser 560:237-242

Knoth C, Klein B, Prinz T, Kleinebecker T (2013) Unmanned aerial vehicles as innovative remote sensing platforms for high-resolution infrared imagery to support restoration monitoring in cut-over bogs. Appl Veg Sci 16: 509-517

Koh LP, Wich SA (2012) Dawn of drone ecology: low-cost autonomous aerial vehicles for conservation. Trop Conserv Sci 5:121-132

Kuenzer C, Ottinger M, Wegmann M, Guo H and others (2014) Earth observation satellite sensors for biodiversity monitoring: potentials and bottlenecks. Int $\mathrm{J}$ Remote Sens 35:6599-6647

Kal A, Arthur R, Marbà N, Lill AWT, Alcoverro T (2010) Implications of conserving an ecosystem modifier: increasing green turtle (Chelonia mydas) densities substantially alters seagrass meadows. Biol Conserv 143: 2730-2738

KLathrop RG, Montesano P, Haag S (2006) A multi-scale segmentation approach to mapping seagrass habitats using airborne digital camera imagery. Photogramm Eng Remote Sensing 72:665-675

KLauret-Stepler M, Bourjea J, Roos D, Pelletier D, Ryan PG, Ciccione S, Grizel H (2007) Reproductive seasonality and trend of Chelonia mydas in the SW Indian Ocean: a 20 yr study based on track counts. Endang Species Res 3: $217-227$

* Lhoest S, Linchant J, Quevauvillers S, Vermeulen C, Lejeune $P$ (2015) How many hippos (HOMHIP): algorithm for automatic counts of animals with infra-red thermal imagery from UAV. Proceedings of the ISPRS Geospatial Week, La Grande Motte, France. Int Arch Photogramm Remote Sens XL-3/W3:355-362

* Linchant J, Lisein J, Semeki J, Lejeune P, Vermeulen C (2015) Are unmanned aircraft systems (UASs) the future of wildlife monitoring? A review of accomplishments and challenges. Mammal Rev 45:239-252

* Long N, Millescamps B, Guillot B, Pouget F, Bertin X (2016) Monitoring the topography of a dynamic tidal inlet using UAV imagery. Remote Sens 8:387

* Long TM, Angelo J, Weishampel JF (2011) LiDAR-derived measures of hurricane- and restoration-generated beach morphodynamics in relation to sea turtle nesting behaviour. Int J Remote Sens 32:231-241

* Mancini F, Dubbini M, Gattelli M, Stecchi F, Fabbri S, Gabbianelli G (2013) Using unmanned aerial vehicles (UAV) for high-resolution reconstruction of topography: the structure from motion approach on coastal environments. Remote Sens 5:6880-6898

Metcalfe K, Agamboue PD, Augowet E, Boussamba F and others (2015) Going the extra mile: Ground-based monitoring of olive ridley turtles reveals Gabon hosts the largest rookery in the Atlantic. Biol Conserv 190:14-22

* Michez A, Morelle K, Lehaire F, Widar J, Authelet M, Vermeulen C, Lejeune P (2016) Use of unmanned aerial system to assess wildlife (Sus scrofa) damage to crops (Zea 
mays). J Unmanned Veh Syst 4:266-275

Miller JD (1997) Reproduction in sea turtles. In: Lutz P, Musick J (eds) The biology of sea turtles. CRC Press, Boca Raton, FL, p 51-81

Milton SL, Lutz PL (2003) Physiological and genetic responses to environmental stress. In: Lutz PL, Musick JA, Wyneken J (eds) The biology of sea turtles, Vol 2. CRC Press, Boca Raton, FL, p 163-197

Miyamoto M, Yoshino K, Nagano T, Ishida T, Sato Y (2004) Use of balloon aerial photography for classification of Kushiro wetland vegetation, northeastern Japan. Wetlands 24:701-710

Mulero-Pázmány M, Stolper R, van Essen LD, Negro JJ, Sassen T (2014) Remotely piloted aircraft systems as a rhinoceros anti-poaching tool in Africa. PLOS ONE 9: e83873

* Mumby PJ, Green EP, Edwards AJ, Clark CD (1999) The cost-effectiveness of remote sensing for tropical coastal resources assessment and management. J Environ Manage 55:157-166

Nachtsheim DA, Jerosch K, Hagen W, Plötz J, Bornemann H (2017) Habitat modelling of crabeater seals (Lobodon carcinophaga) in the Weddell Sea using the multivariate approach Maxent. Polar Biol 40:961-976

Olivares-Mendez MA, Fu C, Ludivig P, Bissyandé TF and others (2015) Towards an autonomous vision-based unmanned aerial system against wildlife poachers. Sensors (Basel) 15:31362-31391

Phinn S, Roelfsema C, Dekker A, Brando V, Anstee J (2008) Mapping seagrass species, cover and biomass in shallow waters: an assessment of satellite multi-spectral and airborne hyper-spectral imaging systems in Moreton Bay (Australia). Remote Sens Environ 112:3413-3425

Piniak WED, Mann DA, Eckert SA, Harms CA (2012) Amphibious hearing in sea turtles. In: Popper AN, Hawkins A (eds) The effects of noise on aquatic life. Springer, New York, NY, p 83-87

* Puttock AK, Cunliffe AM, Anderson K, Brazier RE (2015) Aerial photography collected with a multirotor drone reveals impact of Eurasian beaver reintroduction on ecosystem structure. J Unmanned Veh Syst 3:123-130

Rees AF, Margaritoulis D, Newman R, Riggall TE and others (2013) Ecology of loggerhead marine turtles Caretta caretta in a neritic foraging habitat: movements, sex ratios and growth rates. Mar Biol 160:519-529

* Rees AF, Alfaro-Shigueto J, Barata PCR, Bjorndal KA and others (2016) Are we working towards global research priorities for management and conservation of sea turtles? Endang Species Res 31:337-382

Rees AF, Varela MR, Godley BJ (2017) The use of unmanned aerial vehicles (UAVs) in sea turtle research: a workshop report. Mar Turtle Newsl 154:20-21

Reina RD, Mayor PA, Spotila JR, Piedra R, Paladino FV (2002) Nesting ecology of the leatherback turtle, Dermochelys coriacea, at Parque Nacional Marino Las Baulas, Costa Rica: 1988-89 to 1999-2000. Copeia 2002:653-664

Samuel Y, Morreale SJ, Clark CW, Greene CH, Richmond ME (2005) Underwater, low-frequency noise in a coastal sea turtle habitat. J Acoust Soc Am 117:1465-1472

Sandbrook C (2015) The social implications of using drones for biodiversity conservation. Ambio 44(Suppl 4): 636-647

Sasse DB (2003) Job-related mortality of wildlife workers in the United States, 1937-2000. Wildl Soc Bull 31: 1000-1003
Sayyed A, de Araújo G, Bodanese J, Becker L (2015) Dualstack single-radio communication architecture for UAV acting as a mobile node to collect data in WSNs. Sensors (Basel) 15:23376-23401

Schofield G, Katselidis KA, Dimopoulos P, Pantis JD, Hays GC (2006) Behaviour analysis of the loggerhead sea turtle Caretta caretta from direct in-water observation. Endang Species Res 2:71-79

Schofield G, Katselidis KA, Lilley MKS, Reina RD, Hays GC (2017a) Detecting elusive aspects of wildlife ecology using drones: new insights on the mating dynamics and operational sex ratios of sea turtles. Funct Ecol 31: 2310-2319

K Schofield G, Papfitsoros K, Haughey R, Katselidis K (2017b) Aerial and underwater surveys reveal temporal variation in cleaning-station use by sea turtles at a temperate breeding area. Mar Ecol Prog Ser 575:153-164

Schroeder B, Murphy S (1999) Population surveys (ground and aerial) on nesting beaches. In: Eckert KL, Bjorndal KA, Abreu-Grobois FA, Donnelly M (eds) Research and management techniques for the conservation of sea turtles. IUCN/SSC Marine Turtle Specialist Group Publication No. 4. IUCN, Washington, DC, p 45-55

Seminoff JA, Eguchi T, Carretta J, Allen CD and others (2014) Loggerhead sea turtle abundance at a foraging hotspot in the eastern Pacific Ocean: implications for atsea conservation. Endang Species Res 24:207-220

Seymour AC, Dale J, Hammill M, Halpin PN, Johnston DW (2017) Automated detection and enumeration of marine wildlife using unmanned aircraft systems (UAS) and thermal imagery. Sci Rep 7:45127

* Sheppard CRC, Matheson K, Bythell JC, Murphy P, Myers CB, Blake B (1995) Habitat mapping in the Caribbean for management and conservation: use and assessment of aerial photography. Aquat Conserv 5:277-298

Smolowitz RJ, Patel SH, Haas HL, Miller SA (2015) Using a remotely operated vehicle (ROV) to observe loggerhead sea turtle (Caretta caretta) behavior on foraging grounds off the mid-Atlantic United States. J Exp Mar Biol Ecol 471:84-91

Strecha C, Fletcher A, Lechner A, Erskine P, Fua P (2012) Developing species specific vegetation maps using multi-spectral hyperspatial imagery from unmanned aerial vehicles. ISPRS Annal Photogram Remote Sens Spat Inf Sci I-3:311-316

Strindberg S, Coleman RA, Burns Perez VR, Campbell CL, Majil I, Gibson J (2016) In-water assessments of sea turtles at Glover's Reef Atoll, Belize. Endang Species Res 31: 211-225

* Sykora-Bodie ST, Bezy V, Johnston DW, Newton E, Lohmann KJ (2017) Quantifying nearshore sea turtle densities: applications of unmanned aerial systems for population assessments. Sci Rep 7:17690

Tavakoli S, Heaton A, Ansell D, Poslad S (2016) Wildlife tracking on the wing using unmanned air vehicles. In: AIAA SciTech Forum 2016-0919, San Diego, CA, 4-8 January 2016. American Institute of Aeronautics and Astronautics, Reston, VA

*Theuerkauf EJ, Rodriguez AB, Fegley SR, Luettich RA (2014) Sea level anomalies exacerbate beach erosion. Geophys Res Lett 41:5139-5147

* Thomson JA, Cooper AB, Burkholder DA, Heithaus MR, Dill LM (2013) Correcting for heterogeneous availability bias in surveys of long-diving marine turtles. Biol Conserv 165:154-161 
Thums M, Waayers D, Huang Z, Pattiaratchi C, Bernus J, Meekan M (2017) Environmental predictors of foraging and transit behaviour in flatback turtles Natator depressus. Endang Species Res 32:333-349

van Gemert JC, Verschoor CR, Mettes P, Epema K, Koh LP, Wich S (2015) Nature conservation drones for automatic localization and counting of animals. In: Agapito L, Bronstein M, Rother C (eds) Computer vision - ECCV 2014 Workshops, Part 1. Lecture Notes in Computer Science, Vol 8925. Springer, Cham, p 255-270

Ventura D, Bruno M, Lasinio GJ, Belluscio A, Ardizzone G (2016) A low-cost drone based application for identifying and mapping of coastal fish nursery grounds. Estuar Coast Shelf Sci 171:85-98

Ventura D, Bonifazi A, Gravina MF, Ardizzone G (2017) Unmanned aerial systems (UASs) for environmental monitoring: a review with applications in coastal habitats. In: Lopez Mejia OD (ed) Aerial robots-aerodynamics, control and applications. InTech, London, p 165-184

Verutes GM, Huang C, Estrella RR, Loyd K (2014) Exploring scenarios of light pollution from coastal development reaching sea turtle nesting beaches near Cabo Pulmo, Mexico. Glob Ecol Conserv 2:170-180

Vincent J, Werden LK, Ditmer MA (2015) Barriers to adding UAVs to the ecologist's toolbox. Front Ecol Environ 13: 74-75

Wabnitz CC, Andréfouët S, Torres-Pulliza D, Müller-Karger FE, Kramer PA (2008) Regional-scale seagrass habitat mapping in the wider Caribbean region using Landsat

Editorial responsibility: Rory Wilson,

Swansea, UK sensors: applications to conservation and ecology. Remote Sens Environ 112:3455-3467

*Wang C, Ma F, Yan J, De D, Das SK (2015) Efficient aerial data collection with UAV in large-scale wireless sensor networks. Int J Distrib Sens Netw 11:286080

Watts AC, Ambrosia VG, Hinckley EA (2012) Unmanned aircraft systems in remote sensing and scientific research: classification and considerations of use. Remote Sens 4:1671-1692

* Weber SB, Weber N, Godley BJ, Pelembe T, Stroud S, Williams N, Broderick AC (2017) Ascension Island as a mid-Atlantic developmental habitat for juvenile hawksbill turtles. J Mar Biol Assoc UK 97:813-820

*Williams JL, Pierce SJ, Fuentes MMPB, Hamann M (2015) Effectiveness of recreational divers for monitoring sea turtle populations. Endang Species Res 26:209-219

* Wilson C, Tisdell C (2001) Sea turtles as a non-consumptive tourism resource especially in Australia. Tour Manage 22:279-288

* Witherington B, Kubilis P, Brost B, Meylan A (2009) Decreasing annual nest counts in a globally important loggerhead sea turtle population. Ecol Appl 19:30-54

* Witt MJ, Baert B, Broderick AC, Formia AC and others (2009) Aerial surveying of the world's largest leatherback turtle rookery: a more effective methodology for large-scale monitoring. Biol Conserv 142:1719-1727

* Yamamoto KH, Powell RL, Anderson S, Sutton PC (2012) Using LiDAR to quantify topographic and bathymetric details for sea turtle nesting beaches in Florida. Remote Sens Environ 125:125-133

Submitted: September 5, 2017; Accepted: December 2, 2017 Proofs received from author(s): February 6, 2018 